\title{
Publishers go head-to-head over search tool
}

Jim Giles, London

Will there ever be a science equivalent of Google? Two of the world's biggest science publishing and information firms seem to think that there will. They are about to compete head-to-head to create the most popular tool for searching the scientific literature.

Elsevier, the Amsterdam-based publisher of more than 1,800 journals, has announced that this autumn it will launch Scopus, an online search engine covering abstracts and references from 14,000 scientific journals. Scopus will arrive as a direct competitor for the established Web of Science, owned by Thomson ISI of Philadelphia, the scientific information specialist.

"Scopus will definitely be a threat to ISI," says one science publishing expert, who asked not to be named. "But ISI will not just let this happen. There will be some kind of arms race in terms of adding new features."

Many researchers are already wedded to subject-specific databases of scientific information, such as PubMed, for biomedical research. But Web of Science is currently the only service to cover the full spectrum of scientific disciplines and publications. It can also generate the citation statistics that are sometimes used to measure the quality of journals and individual papers.

ISI, which is widely used by libraries worldwide, may be hard to displace. It covers fewer than 9,000 journals, but it has been available in its present form since 1997 and includes a 60-year archive of papers. Thomson ISI says it will extend this to 105 years by

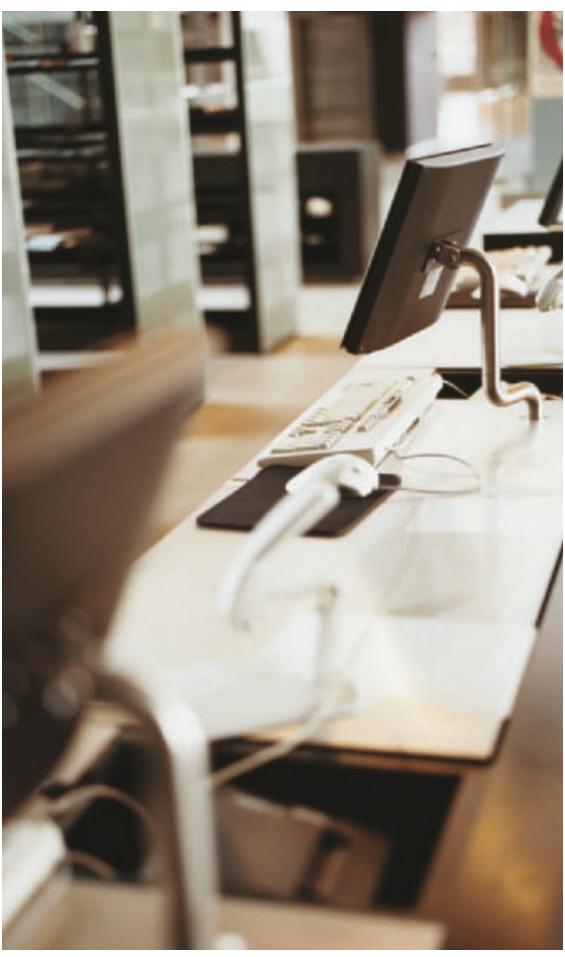

Definitive database? Scopus and Web of Science will help scientists search the literature.

the end of 2005. The company also owns the only extensive database on patent abstracts.

Elsevier cannot hope to match this coverage in the short term. The company has been able to draw on its experience of running biomedical and pharmaceutical databases, and developers began compiling a multidisci- plinary index two years ago. Even so, when it launches, Scopus will index only five years of references for some journals, rising to ten years during 2005. Data on abstracts will go back further, in some cases to the mid-1960s.

Because Scopus has been built from scratch, Elsevier has been able to work with librarians to develop an alternative to the Web of Science interface, which has been criticized by some users. "Users are very happy with Scopus," says Steven Gheyselinck, a librarian at the University of Lausanne in Switzerland who has been testing it.

Although Scopus and Web of Science are the only products aiming to cover all of science, other search engines are also under development. The Google of science could end up being Google itself: the company has collaborated with nine publishers, including Nature Publishing Group, to create an engine called CrossRef Search.

This service, a pilot of which appeared last month, allows users to search digital versions of all papers held by the publishers involved and returns links to articles on their websites. Unlike Web of Science and Scopus, which scan through the titles and abstracts of articles, CrossRef Search also searches the full text of papers. Many of the other 300 or so members of CrossRef - a publishers' collaboration established to allow easier linking between citations - are likely to join the service if the pilot is successful.

\section{www.isinet.com}

www.crossref.org/crossrefsearch.html

www.scopus.com

\section{Six-day sacking over as researcher regains Italian job}

\section{Alison Abbott, Munich}

It was no joke when Lucio Luzzatto was told on 1 April that he was being sacked as scientific director of Italy's National Cancer Institute in Genoa - even though he was reinstated by the health ministry just six days later.

The institute's temporary commissioner, Maurizio Mauri, sacked Luzzatto after accusing him of breaking the terms of his contract by acting as a consultant for his former employer, the Memorial SloanKettering Cancer Center in New York. Mauri later accepted that only industrial consultancies were disallowed.

Luzzatto says that he was the victim of a battle over whether a research institute should be run by scientists or administrators. But many of his supporters say he fell foul of the Byzantine politics that permeate Italian science and academia.

Mauri was appointed in 2001 to hold the reins while a new management structure was implemented at the National Cancer Institute, one of Italy's 32 clinical research institutes, whose restructuring has been delayed for more than a decade. During this time, each institute has been in the hands of commissioners who have full administrative control. A law was passed last year to let the institutes run themselves again but this has yet to be implemented.

Mauri charged that Luzzatto broke the terms of his contract by working with the Sloan-Kettering centre, which he left in 2000 to take up his post in Genoa. Luzzatto argues that such collaborations are both normal and desirable in academic research, and points out that he spent a total of only 16 days in New York last year. Scientists throughout Italy wrote to the health ministry in his defence, attesting to his dedication to the Genoa institute.

At a meeting on 6 April, the ministry accepted Luzzatto's arguments and Mauri retracted his letter of dismissal. But Luzzatto says he remains under strong pressure to leave the institute voluntarily. In an attempt to defuse the tensions, the local government of Liguria has offered to finance an independent laboratory for him.

Luzzatto suspects that the real reasons for the dismissal were his disagreements with Mauri about how the institute should be run. One such dispute concerned Mauri's decision to claw back salary supplements from $\mathrm{PhD}$ scientists that are legally applicable only to those with MDs. Luzzatto had argued that it would be demoralizing to have different pay for the same work within a lab.

"Italy says it wants to reverse the brain drain - it is appalling that a top scientist who returns to Italy should be treated in this way," comments Giovanni Romeo, a medical geneticist at the University of Bologna. 